\begin{tabular}{|} 
Ambiente \& Água - An Interdisciplinary Journal of Applied Science \\
ISSN 1980-993X - doi:10.4136/1980-993X \\
www.ambi-agua.net \\
E-mail: ambi.agua@gmail.com
\end{tabular}

\title{
Indicadores de produtividade aplicados à pesca artesanal do camarão sete-barbas, Penha, SC, Brasil
}

\author{
doi:10.4136/ambi-agua.1659
}

Received: 08 May 2015; Accepted: 21 Nov. 2015

\section{Vicente Francisco Coelho $^{1 *}$; Joaquim Olinto Branco ${ }^{2}$; Marco Antonio Harms Dias ${ }^{2}$}

\author{
Universidade do Vale do Itajaí (UNIVALI), Itajaí, SC, Brasil \\ ${ }^{1}$ Programa de Pós-Graduação em Ciência e Tecnologia Ambiental \\ ${ }^{2}$ Centro de Ciências Tecnológicas da Terra e do Mar (CCTMar) \\ *Autor correspondente: e-mail: vicacoelho@hotmail.com, \\ branco@univali.br,mdias@univali.br
}

\section{RESUMO}

Utilizando ferramentas da contabilidade ambiental para coleta e organização de informações, referentes ao mercado e organização do trabalho da comunidade de pescadores artesanais de Penha, SC, realizou-se a pesquisa de forma descritiva e exploratória das práticas produtivas. Esta pesquisa baseou-se em duas fontes de dados e referências bibliográficas para padronização de informações. Calcularam-se indicadores de produtividade, objetivando avaliar a possibilidade do uso deles na gestão ambiental do recurso. Foram levantados os insumos consumidos, custos, quantidades produzidas e comercializadas, destinos e valores de venda, sazonalidade de esforço e capturas. Com base neles, foi possível se calcular indicadores de produtividade ambiental e econômica, em ciclos mensais e anuais, que permitiram evidenciar o período de defeso. Tais métodos exigem muito esforço em coleta e controle de dados, sobretudo em uma comunidade tradicional de pesca artesanal desassociada de rígidos controles necessários essenciais ao estudo sistêmico da produtividade e da organização econômica.

Palavras-chave: gestão da produção, contabilidade ambiental, Xiphopenaeus kroyeri.

\section{Productivity indicators applied to seabob shrimp fishing, Penha SC, Brazil}

\section{ABSTRACT}

This study used environmental accounting tools to collect and organize information related to the market and work organization of the artisan fishing community of Penha, SC. This research was based on two sources of data and references to standardize information. We calculated productivity indicators and evaluated the possibility of using them for environmental management of this resource. We calculated the consumed inputs, costs, produced and marketed quantities, destinations and sales values, and the seasonality of effort and catches. Based upon these, it was possible to calculate indicators of environmental and economic productivity, in monthly and annual cycles that allowed us to identify the best periods in which to close the shrimp harvesting season. Such methods, however, require great 
effort for data collection and tracking, especially in a traditional community of artisanal fisheries lacking the strict control needed for systemic study of productivity and economic organization.

Keywords: environmental accounting, production management, Xiphopenaeus kroyeri.

\section{INTRODUÇÃO}

A pesca artesanal é uma das principais atividades, tradicionalmente realizada no município de Penha SC (26 46'10' S 48 $38^{\circ}$ '45'), que envolve um elevado contingente de famílias, especialmente dependentes da pesca de arrasto do camarão sete-barbas (Xiphopenaeus kroyeri) (Branco, 2005). Com uma área de $60,3 \mathrm{~km}^{2}$, esse município teve seu desenvolvimento social e econômico inicial, centrado na pesca. Atualmente, conta com uma população de 28 mil habitantes e IDHM de 0,743 e PIB per capta de R\$ 14.784,68 (IBGE, 2015).

Modelos artesanais de pesca e aquicultura são relevantes, ao empregar $90 \%$ da força de trabalho e contribuir com $50 \%$ da produção mundial do setor pesqueiro (Carneiro et al., 2014). A pesca do camarão sete-barbas (Xiphopenaeus kroyeri), por sua importância na geração de renda e alimento (Bail e Branco, 2007), pode ser considerada um patrimônio natural, ativo ambiental, e juntamente com a cultura de trabalho dos pescadores artesanais de Penha, um bem comum no litoral catarinense, que ainda demanda planos de monitoramento e políticas públicas adequadas de gestão. Fundamentado em seu valor intrínseco como patrimônio biológico, o camarão deve ser conservado pela importância ecológica e valor antropogênico, ao sustentar todo um modo de vida (Alho, 2008).

As políticas públicas voltadas à pesca ainda não conseguem promover uma gestão deste patrimônio, ao excluir aspectos intrínsecos à atividade da pesca artesanal, como mercado e organização do trabalho (Carneiro et al., 2014). O presente trabalho visa preencher essa lacuna informacional, com contribuição de agentes da comunidade de pescadores de Penha, SC. Os participantes, voluntários, ao responder os questionamentos acerca de seus métodos de produção, possibilitaram o início de um entendimento dessas questões.

A administração da produção, além de contribuir para o entendimento e a organização do trabalho, procura atender a relação custo-benefício, na perspectiva econômica (Pfitscher, 2004; Martins e Laugeni, 2006). Entretanto a crescente conscientização ambiental da sociedade tem provocado cobrança das ações e responsabilidade de conduta das organizações, dos três setores, que intervém no meio ambiente (Silva Gomes et al., 2012). Nesse contexto surge a contabilidade ambiental, com ferramentas de gestão, buscando suprir informações sobre ativos e passivos ambientais intrínsecos ao sistema produtivo, respectivamente, elementos de origem natural ou biológica capazes de gerar benefícios econômicos e custos relacionados ao consumo desses, bem como os relacionados à produção indesejada de insumos, emissões e descartes (Cruz et al., 2009).

A aplicação desta ferramenta ainda não atingiu seu estado da arte no contexto ambiental. Publicações relacionadas ainda não conseguem responder adequadamente toda a complexidade do tema (Reis et al., 2011), principalmente as centradas em sustentabilidade, que procuram evidenciar macro processos administrativos e econômicos em gestão de grandes grupos empresariais (Araujo e Ramos, 2015). Entretanto, associada a dados de produtividade, pode demonstrar a redução de custos ambientais e uso eficiente dos recursos naturais (Pfitscher, 2004; Silva e Cruz, 2014).

A produtividade é uma medida de desempenho muito comum na administração da produção, seu cálculo é simples e o resultado expressa um indicador de eficiência, entretanto sua complexidade está associada à delimitação sistêmica dos processos produtivos e a 
contabilização de suas entradas: recursos, máquinas, energia, sistemas, equipamentos e pessoas, bem como as saídas: produtos e subprodutos na forma de bens ou serviços, descartes e emissões (Martins e Laugeni, 2006). Desta forma, não estão diretamente associados aos conceitos de ativo e passivo ambientais, por exemplo, o camarão que "entra" no processo de pesca como um ativo, a gerar valor posteriormente durante a comercialização. Ou um efluente que "sai” de uma atividade qualquer, com custo para seu tratamento, portanto um passivo.

No contexto ambiental, o uso do indicador de produtividade material, não se trata necessariamente de uma forma de medir impacto, entendendo esse como taxas de transformação do ambiente inerentes à realização da atividade antropogênica (Kristensen, 2004). Dado às relações de causa e efeito dos processos produtivos (Campos, 2004), pode ser tratada como uma medida de pressão ambiental (Kristensen, 2004), onde processos mais eficientes podem resultar, por exemplo, em menor consumo de madeira por quilograma de camarão pescado, o que por definição é positivo, contudo não impede o corte de arvores.

Esse trabalho ao utilizar pressupostos da contabilidade ambiental, para organizar informações intrínsecas à atividade produtiva da pesca artesanal, com a finalidade de possibilitar o cálculo de indicadores de produtividade, a partir de um estudo de caso, objetiva avaliar a possibilidade de uso desses indicadores na gestão ambiental de um recurso visto como um bem comum, e, dessa forma, evidenciar críticas aos métodos de controle de dados no contexto da pesca artesanal.

\section{MATERIAL E MÉTODOS}

Com o uso de técnicas de levantamento de dados, foram realizadas entrevistas estruturadas, sobre fundamentos metodológicos clássicos da administração da produção, para delimitação sistêmica dos processos produtivos (Martins e Laugeni, 2006). A qual é iniciada com a definição do processo de pesca, que inicia quando o pescador sai com a embarcação, finalizando com o desembarque e acondicionamento do produto pescado, com potencial de comercialização - saída de ativo ambiental da atividade. Tem como entrada: a biomassa total extraída e uma embarcação adequada ao uso (óleo diesel, gelo e trabalho do pescador).

Para que a embarcação esteja em condições adequadas ao uso, são necessários processos de apoio ao funcionamento da pesca como reparos nos motores, pintura e manutenção de cascos. Como entradas desses, embarcações com deficiência em seus sistemas de flutuação, propulsão ou com necessidade de pintura, bem como: madeira, tinta, óleo lubrificante, horas de serviço de profissionais especializados ou dos próprios pescadores.

A intervenção em campo ocorreu no município de Penha, SC, em local previamente identificado (Bail e Branco, 2007), como praia, rancho de pesca, trapiches, peixaria e, em alguns casos, nas próprias residências dos pescadores. Contando com uma amostra não probabilística, sobre 30 pescadores artesanais, de um total de 60 atuantes na cooperativa local, em 2012. A partir dessa, foi possível levantar custos, quantidades e a frequência média demandada dos serviços e insumos, sobre os quais foi calculada a média mensal de consumo de cada item. Entretanto os dados materiais foram indicados em uma grande variedade de unidades de medida de volume, a exemplo, embalagens de dois litros de tinta, de um litro de óleo e metros lineares de madeira.

A transformação dos dados volumétricos para quilogramas ocorreu com auxílio de bibliografia especializada. Para óleos lubrificantes e tintas, especificações de densidade obtidas em fichas técnicas de produtos similares (Petrobras, 2011; International Paint, 2009a; 2009b). Já a madeira, tanto a usada em manutenção, quanto o total da frota, foram estimadas com auxilio de um manual de construção de embarcações de madeira (FAO, 2008).

Também, foram utilizados dados coletados em 2010 de 81 pescadores e 71 embarcações, procedentes de cinco mil controles de diário de bordo, no município de Penha, SC, cedidos 
pela Empresa de Pesquisa Agropecuária e Extensão Rural de Santa Catarina (Epagri), que forneceram informações de quantidades e valores, produzidos e comercializados ao longo dos meses, bem como o destino da comercialização desses (atravessadores, peixarias e etc.). Além da produção, forneceu dados da sazonalidade de esforço, como consumo de óleo diesel e serviços de pesca.

A produtividade é calcula através da divisão de saídas por entradas, de acordo com o escopo da análise (Martins e Laugeni, 2006). No presente estudo foi calculada sobre o somatório total das entradas e saídas, ao longo dos meses, não considerando a fauna acompanhante, em duas unidades de medidas: quilogramas e reais, respectivamente, produtividade material (pressão ambiental) e produtividade econômica (rentabilidade).

\section{RESULTADOS E DISCUSSÃO}

O principal desafio em utilizar indicadores de produtividade numa comunidade tradicional de pescadores, não está na forma de cálculo, mas na sistemática de controle dos dados. A contabilidade, aplicada ao contexto ambiental, tem caráter interdisciplinar, procurando analisar informações, que auxiliem os gestores na definição de metas ambientais (Silva Gomes et al., 2012). Demandas que, além de exigir um gestor capacitado a lidar com questões técnicas econômicas e ambientais, exige dos pescadores participação do processo de monitoramento, transparência com as informações e equidade de atuação.

\subsection{Organização econômica dos pescadores artesanais}

As embarcações foram reparadas, a cada $36 \pm 23$ meses, pintadas anti-incrustações com $6 \pm 4$, tinta comum em $12 \pm 5$ meses, e os motores receberam manutenção em $45 \pm 17$ meses.

As atividades de apoio combinadas consomem 16\% do volume material, nas quais o item madeira representa $11 \%\left(10 \mathrm{t} \mathrm{ano}^{-1}\right)$; enquanto que, no processo da pesca estima-se um consumo de $77 \mathrm{t}_{\text {ano }}{ }^{-1}$ de óleo diesel ou $79 \%$ da massa de insumos, que representa em torno de 189 mil reais e $49 \%$ do valor total (Tabela 1). Todas as atividades de manutenção consomem aproximadamente $51 \%$ do montante de recursos financeiros aplicados na operação. Os valores foram levantados a partir do valor médio de mercado para cada item e estão expressos em Reais ( $\mathrm{R} \$)$.

A Tabela 1 apresenta-se sobre uma lógica de processo produtivo, considerando seus principais insumos, esforço de trabalho e suas relações econômicas, denominados de “entradas” para cada embarcação, em unidades, quilogramas, semanas de trabalho, horas de pesca e valores. Para uma real avaliação do impacto na comunidade os dados são explicitados por embarcação e frota. Considerou-se como frota pesqueira dessa comunidade a quantidade de 52 embarcações, pois foi o maior registro de operação no período de maior intensidade, nos meses de junho e julho.

Do total de produto pescado, apenas o montante comercializado, aproximadamente 205 toneladas de camarão sete-barbas (valor médio 3,22 $\mathrm{R} \$ \mathrm{~kg}^{-1}$ ) e $40 \mathrm{t}$ de outras espécies $\left(2,85 \mathrm{R} \$ \mathrm{~kg}^{-1}\right.$ ) (Tabela 2) perfazem um faturamento aproximado de 782.083,00 R\$ ano-1 . Os principais compradores são os atravessadores, mercados de peixes locais e peixarias.

Dentre os produtos comercializados, existem diferenças no valor e quantidade destinada a compradores (113 t a 2,91 $\mathrm{R} \$ \mathrm{~kg}^{-1}$ para atravessadores e $1,7 \mathrm{t}$ a $4,90 \mathrm{R} \$ \mathrm{~kg}^{-1}$ para consumidor final), evidenciando possíveis estratégias de ganho de produtividade, apenas pelo controle e redirecionamento de oferta (Ritzman e Krajewski, 2004; Martins e Laugeni, 2006). Contudo, os pescadores atuam de forma individual, diminuindo suas capacidades de barganhas nas negociações mercadológicas. 
Tabela 1. Entradas de materiais e serviços e sua relação econômica, em um ano de captura do camarão sete-barbas, na Armação do Itapocoroy, Penha.

\begin{tabular}{|c|c|c|}
\hline Entradas & Consumo embarcação & Consumo frota \\
\hline \multicolumn{3}{|c|}{ Materiais $\left(\mathrm{kg} \mathrm{ano}^{-1}\right)$} \\
\hline Madeira & 206,25 & $10.725,00$ \\
\hline Tinta Comum & 31,64 & $1.645,28$ \\
\hline Tinta Anti-incrustante & 11,80 & 613,60 \\
\hline Consumo de Óleo Lubrificante & 29,26 & $1.521,52$ \\
\hline Diesel & $1.488,75$ & $77.415,00$ \\
\hline Gelo & 124,20 & $6.458,40$ \\
\hline Camarão sete-barbas & $4.151,35$ & $215.870,30$ \\
\hline Outras Espécies & 785,66 & $40.854,20$ \\
\hline Total & $6.828,91$ & $355.103,30$ \\
\hline \multicolumn{3}{|c|}{ Trabalho (Semanas ano ${ }^{-1}$ ) } \\
\hline Serviço de marceneiro & 1,19 & 61,88 \\
\hline Serviço de Pintura & 1,50 & 78,00 \\
\hline Serviço mecânico & 0,37 & 19,24 \\
\hline Total & 3,06 & 159,12 \\
\hline Serviço de pesca (Horas ano ${ }^{-1}$ ) & $1.147,10$ & $59.649,20$ \\
\hline \multicolumn{3}{|c|}{ Econômico $\left(\mathrm{R} \$ \mathrm{ano}^{-1}\right)$} \\
\hline Madeira & 832,76 & 43.303,52 \\
\hline Serviço de marceneiro & 714,81 & $37.170,12$ \\
\hline Tinta Comum & 508,24 & $26.428,48$ \\
\hline Tinta Anti-incrustante & 310,00 & $16.120,00$ \\
\hline Peças de Reposição & 713,33 & $37.093,16$ \\
\hline Serviço mecânico & 193,33 & $10.053,16$ \\
\hline Consumo de Óleo Lubrificante & 450,08 & $23.404,16$ \\
\hline Diesel & $3.631,09$ & $188.816,68$ \\
\hline Gelo & 61,40 & $3.192,80$ \\
\hline Total & $7.415,04$ & $385.582,08$ \\
\hline
\end{tabular}

A individualidade na tomada de decisão, dos pescadores, pode acarretar em prejuízos à gestão ambiental, ao controle das informações e ao próprio recurso biológico, desarmônico aos pressupostos de uma adequada gestão de bens comum (Lipietz, 2012). A competição e a necessidade de renda podem conduzir pescadores a negligenciar aspectos ligados ao bem comum a sua volta, que por não pertencer a ninguém, pode ser superexplorado e destruído (Lipietz, 2012). Já uma proposta de monitoramento de dados, para ganhos de produtividade pode estar em risco, antes mesmo de utilizada, caso não haja uma uniformidade da coleta de dados, pois a contabilidade ambiental apenas será eficaz à gestão, caso o controle das informações atenda a critérios de geração e transmissão de informações padronizadas, fidedignas e com agilidade (Kalikoski et al., 2009; Pereira et al., 2011). 
Tabela 2. Destino dos produtos comercializados (saídas) na pesca em um ano de captura, na Armação do Itapocoroy, Penha.

\begin{tabular}{lrrrrrr}
\hline Destino do Produto & \multicolumn{2}{c}{ Camarão sete-barbas } & & \multicolumn{2}{c}{ Outras Espécies } \\
\cline { 2 - 3 } \cline { 6 - 7 } Comercializado & \multicolumn{1}{c}{$\mathrm{kg}$} & \multicolumn{1}{c}{$\mathrm{R} \$$} & & $\mathrm{~kg}$ & $\mathrm{R} \$$ \\
\hline Atravessador & $112.859,50$ & $328.546,00$ & & $3.939,80$ & $8.497,20$ \\
Peixaria & $64.408,50$ & $219.900,80$ & & $27.867,90$ & $81.563,12$ \\
Consumo Próprio & $1.420,50$ & $1.728,00$ & & $2.054,00$ & $5.519,60$ \\
Beneficio Próprio & $15.136,50$ & $69.997,00$ & & $1.940,00$ & $5.100,10$ \\
Benefício de Terceiros & $7.205,00$ & $22.814,50$ & & 325,00 & 328,00 \\
Direto ao Consumidor Final & $1.703,30$ & $8.343,50$ & & $3.737,00$ & 17971,75 \\
Restaurantes & 168,00 & 672,00 & & - & - \\
Sem Informação & $2.922,00$ & $10.118,00$ & & 233,20 & 711,60 \\
Doação & 95,00 & 246,00 & & 190,20 & 26,40 \\
\hline Total de saídas & $\mathbf{2 0 5 . 9 1 8 , 3 0}$ & $\mathbf{6 6 2 . 3 6 5 , 8 0}$ & & $\mathbf{4 0 . 2 8 7 , 1 0}$ & $\mathbf{1 1 9 . 7 1 7 , 8 0}$ \\
\hline
\end{tabular}

Comunidades tradicionais de pescadores têm sua organização social e hierárquica definidas, assim um novo modo de trabalho deve surgir de uma realidade existente (Lipietz, 2012). Conhecer as necessidades individuais deste grupo, forças motrizes do processo, (Kristensen, 2004), é fundamental em uma estratégia de monitoramento de produtividade.

\subsection{Principais fatores que influenciam a produtividade}

O indicador de produtividade não tem uma unidade de medida, pois se trata de uma medida relativa de eficiência. Com o valor de saída de produtos de 246.205,40 kg e entrada de insumos de 355.103,30 kg, resulta em um indicador de produtividade material anual de 0,69, assim, para cada 1,0 kg de insumos materiais que entram no processo, 0,69 kg efetivamente transformam-se em produtos; já com uma produção de 782.083,60 R\$ e custo de 385.582,08 $\mathrm{R}$ \$ obteve-se o indicador de produtividade econômica anual de 2,03, para cada real aplicado no processo retornam 2,03 $\mathrm{R} \$$.

Quanto à produtividade material mensal, apenas em junho $(0,80)$ e julho $(0,71)$ ficaram acima da média anual, enquanto que, maio apresentou a menor eficiência material com um indicador de 0,46. Já a produtividade econômica mensal, confirmou junho como mais produtivo, com um indicador calculado de 5,11. Os meses de fevereiro, julho, agosto e outubro, também se mantiveram acima da média anual (Figura 1).

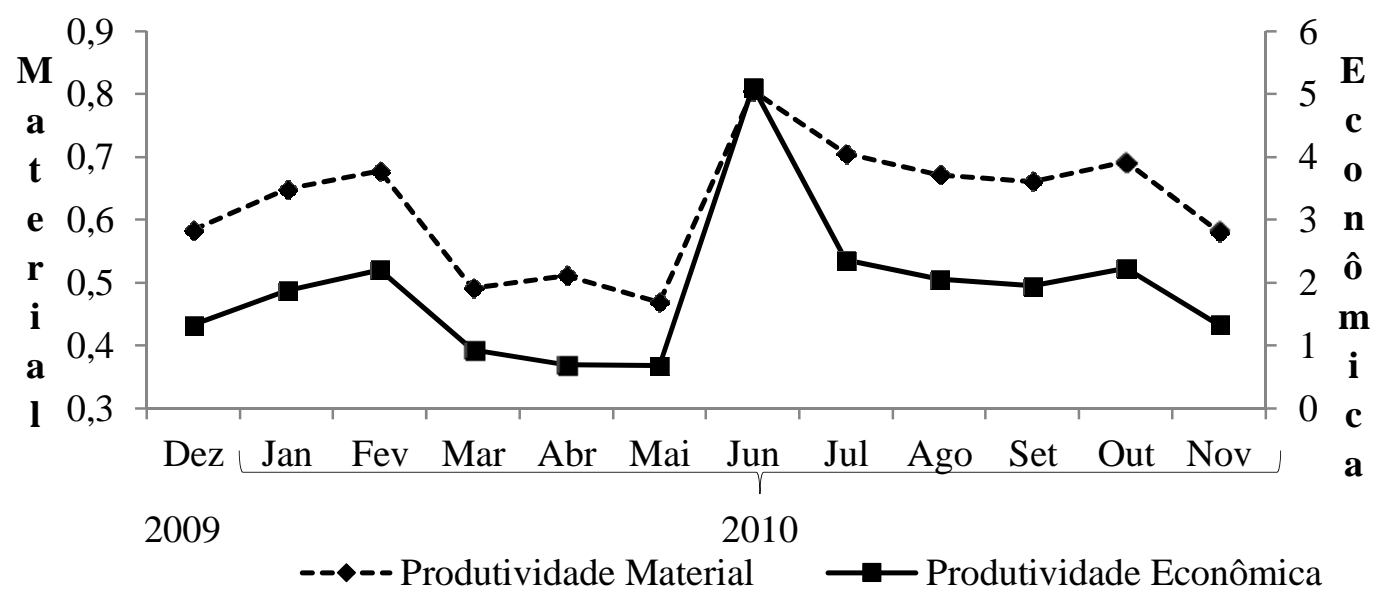

Figura 1. Indicadores de produtividade material e econômica mensais, na pesca de camarão sete-barbas da Armação do Itapocoroy, Penha. 
Na ausência de planos de gestão e estratégias de atuação bem definidas, durante o espaço de tempo analisado, evidenciar o efeito do período de defeso é uma contribuição do método, podendo auxiliar gestores em pesquisas futuras, com uso de indicadores de produtividade na formação de metas estratégicas numéricas e formas de controle direcionando as ações de gestão de forma eficaz (Ritzman e Krajewski, 2004). Mesmo com o grande incremento do esforço, o ganho de eficiência material e econômica após o defeso é significativa, dado um incremento considerável na quantidade produzida.

Existem duas linhas para o ganho de produtividade, aumentar o valor ou a quantidade das saídas ou reduzir os das entradas. Já o uso do indicador exige um controle de dados exato (Kalikoski et al., 2009; Pereira et al., 2011), no caso da pesca o mais rígido possível, sobre os quais deve ser construído um gráfico de produtividade linear ao longo do tempo (Ritzman e Krajewski, 2004). A atividade da gestão passa a ser estratégica, planejando ações para ganhos de produtividade, para que seu sucesso possa ser avaliado graficamente (Campos, 2004; Martins e Laugeni, 2006). Desta forma, por exemplo, a existência de mais de um período de defeso ao ano, poderia resultar em significativa redução de consumo de óleo diesel, para produzir a mesma quantidade total no período. Entretanto a concentração de oferta pode reduzir o preço do produto, jogando contra o incremento de produtividade econômica.

Indicadores de produtividade como ferramenta de gestão ambiental, pode avaliar a viabilidade e o sucesso de diferentes estratégias de pesca, como formas e frequências de atuação sobre pesqueiros, rotas percorridas, tipos de redes, uso de equipamentos, metas de produção e múltiplos períodos de defeso ao longo do ano. Sendo capaz de expressar rentabilidade e pressão ambiental, seu uso pode trazer benefícios ao longo do tempo, através de planejamento, execução, controle e avaliação corretiva, PDCA, de diferentes estratégias para melhoria contínua do processo (Campos, 2004) de forma sustentável, uma vez que permite avaliar tais melhorias em um escopo econômico ecológico (Pfitscher, 2004).

Formular um plano de controle, para cálculo de indicador de produtividade, com base em uma ou mais entradas, depende do escopo de estudo e objetivo estratégico (Martins e Laugeni, 2006). O insumo óleo diesel, com consumo anual aproximado de 77 t (79\%) e 189 mil reais (49\%), é significativo para produtividade material e econômica. Avaliá-lo individualmente, sobretudo sobre o ponto de vista material, ou seja, quantidade de massa produzida por de óleo diesel consumido, pode ser um indicador de pressão ambiental (Kristensen, 2004) relevante ao processo de pesca, facilitando as atividades de controle.

Excluir a fauna acompanhante é fundamental no cálculo do indicador de produtividade ambiental proposto no presente trabalho. Seu volume produzido é tão grande e a eficiência geral do processo é tão baixa que, considerá-la no cálculo, faz com que a linha do gráfico fique horizontal, perdendo seu potencial de indicar a produtividade, uma vez que as varrições dessa passam a ser mínimas (Coelho, 2014). Entretanto a utilização da fauna acompanhante, para gerar renda auxiliar a pesca artesanal do camarão sete-barbas (Branco, 2005; Baile Branco, 2007), é uma alternativa de modernização ecológica de produção e oportunidade bioeconômica, voltadas ao desenvolvimento de tecnologia e processos produtivos, transformando descarte em subproduto (Pereira e González, 2014), que tem como resultado ganhos de produtividade por aumento de produção, saídas de processos (Ritzman e Krajewski, 2004; Martins e Laugeni, 2006).

Aproveitar a fauna acompanhante para aumentar a renda dos pescadores pode ser viável (Branco, 2005; Bail e Branco, 2007), mas não é a única forma de ampliar as saídas do processo produtivo. Estratégias comerciais voltadas à valorização dos produtos podem incrementar a produtividade, sem aumento efetivo da quantidade produzida (Martins e Laugeni, 2006), por meio do aperfeiçoamento dos métodos e valorização das atitudes ambientais que, conforme Pfitscher (2004) são ferramentas eficientes na manutenção do meio ambiente. Nesse sentido, o valor de mercado da biodiversidade, deve considerar não apenas 
os custos operacionais para disponibilização do produto, mas também o valor do sistema de conservação e dos ciclos biológicos, bem como o valor do serviço social e o modo de vida tradicional (Alho, 2008).

\subsection{Sazonalidade de produção}

Os maiores esforços médios mensais de pesca foram praticados em junho (18 dias), logo após o período de defeso do camarão sete-barbas (Figura 2). Juntamente com agosto, meses de inverno, tem a pressão mais intensa da frota artesanal sobre o estoque de camarões, com até 52 embarcações atuando diariamente, reduzindo no verão para 36 a 29 embarcações (dezembro/09, novembro/10), e a poucas no defeso do camarão.

Com a aplicação dos recursos produtivos da pesca, existe a entrada dos recursos naturais através da captura, sendo registradas aproximadamente 216 t de camarão sete-barbas e $41 \mathrm{t}$ de outras espécies, distribuídas entre peixes, moluscos e crustáceos. Quanto à entrada mensal de recursos, junho se destaca como de maior aporte médio diário por embarcação, com aproximadamente $91 \mathrm{~kg}$ de pesca (Figura 3).

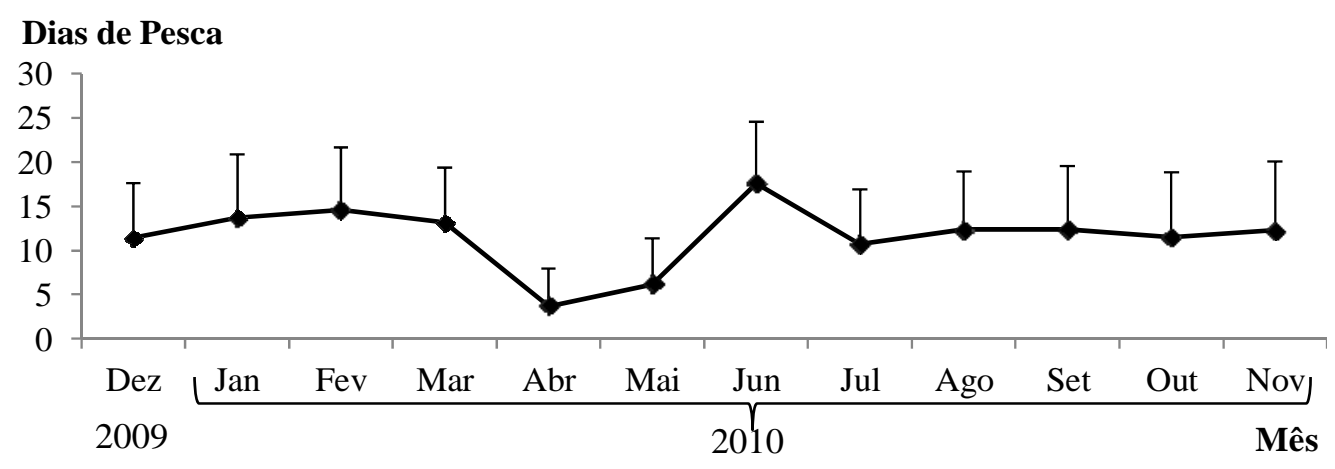

Figura 2. Média de esforço mensal em dias de pesca por embarcação na Armação do Itapocoroy, Penha, SC.

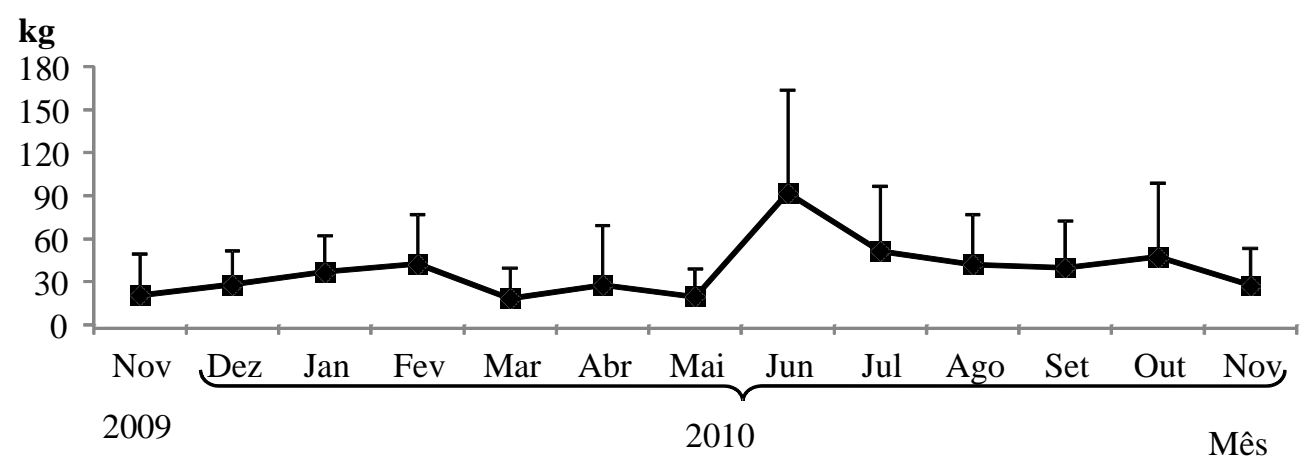

Figura 3. Média diária de produção de pescado por embarcação, na Armação do Itapocoroy, Penha.

Apesar do aumento de entradas com a elevação do esforço em junho, após o defeso do camarão (março, abril e maio), ocorre maior desempenho, eficiência e menor custo por unidade produzida. O efeito dessa interrupção na população é fundamental, pois incrementa a biomassa capturada (Branco, 2005), influenciando a produtividade em junho. Para manutenção do bem comum, controle do esforço de pesca deve passar, portanto, por outras 
medidas: repousos biológicos, fechamentos temporários, medidas técnicas, que já vêm sendo propostas pelos pescadores há muito tempo (Sann, 2012).

Nesse sentido, uso de indicadores mensais, pode se tornar um critério modulador do exercício da atividade, possibilitando comparar a pressão ambiental resultante de diferentes esforços ao longo dos anos (Kristensen, 2004), alterando as metas de atuação operacional e, até mesmo, as sazonalidades de produção. Também o dimensionamento e modernização de frota devem adaptar-se às novas realidades e metas, a fins de gerenciar o bem comum (Sann, 2012).

Um plano de monitoramento de produtividade, com objetivo de gestão do bem comum para a pesca artesanal do camarão em Penha SC, pode embasar-se em alguns pressupostos como metas de produção e um sistema de cotas individuais transferíveis, tal qual proposta pela Comunidade Europeia (Sann, 2012); e um Estado atuando como o guardião do bem comum, obtendo previamente o consentimento esclarecido da comunidade local, antes de conceder-lhe acesso em um processo de redistribuição de resultados, o qual não se trata de uma mera relação mercantil, mas uma recompensa pelo esforço aplicado (Lipietz, 2012).

Pesquisas futuras devem avaliar as forças motrizes do sistema, necessidades individuais e setoriais da pesca artesanal do camarão sete-barbas, dados de estado do meio ambiente (Kristensen, 2004) e suas relações com a produtividade, bem como atuação em sistemas cooperados e individuais.

\section{CONCLUSÃO}

Ao ser capaz de demonstrar os efeitos do defeso, um evento extremamente importante para a pesca artesanal do camarão sete-barbas, os indicadores de produtividade demonstram eficácia para ser aplicado neste contexto. Como indicador de pressão ambiental, pode ser usado exclusivamente para demonstrar o desempenho da atividade antropogênica.

Com melhor desempenho após o defeso, a produção é mais eficiente neste período ecológica e economicamente. O indicador de produtividade material (pressão ambiental) mais elevado, após a parada obrigatória, mostra menor consumo recursos por unidade pescada nesta época, que no resto do ano. Também é mais rentável (produtividade econômica) mesmo com grande incremento de esforço, porém no conjunto, com o mesmo aproveitamento do bem comum no decorrer de um período anual.

Frente à dificuldade para obter informações nesse contexto, evidencia-se que uma forma de simplificar a coleta de dados, para cálculo de indicadores de produtividade material, é com o controle exclusivo das quantidades consumidas de óleo diesel e produzidas de pescado, dado a grande representatividade deste insumo materialmente. Já para o cálculo da rentabilidade é necessário ainda, ao mínimo, os valores de negociação destes insumos e produtos, bem como os custos totais de manutenção de equipamentos e embarcações. No decorrer de médias históricas, com necessidade de replicação desse estudo tanto no mesmo local, quanto em outros similares, poder-se-á avaliar a gestão e preservação desse patrimônio biológico de forma mais abrangente.

A visão tradicional da pesca artesanal está desassociada das rígidas exigências de exatidão da coleta de dados, necessários aos estudos sistêmicos da produtividade e da organização econômica, bem como mensuração de impactos e tendências. Incluir estes processos gerenciais no dia-a-dia desta população tradicional demandará inclusão social, em um processo de educação socioeconômica e ambiental, para proporcionar clareza das metas produtivas, argumentos de vendas e leitura dos resultados. Nesse contexto, entender o patrimônio biológico como bem comum, que pertence a todos e a ninguém, é fundamental para um modelo de pesca mais produtivo, embasado em controle, socialmente justo e sustentável. 


\section{AGRADECIMENTOS}

Os autores gostariam de agradecer ao Programa de Pós-Graduação em Ciência e Tecnologia Ambiental da Universidade do Vale do Itajaí. Ao CNPq (Conselho Nacional de Pesquisa) pela bolsa de produtividade do pesquisador JOB. Ao apoio e disponibilidade de acesso dos pescadores artesanais da localidade de Penha, SC, que permitiram realizar a coleta de dados desse artigo. Bem como as contribuições dos revisores anônimos que contribuíram consideravelmente no trabalho.

\section{REFERÊNCIAS}

ALHO, C. J. R. The value of biodiversity. Brazilian Journal of Biology, v. 68 n. 4. 2008. http://dx.doi.org/10.1590/S1519-69842008000500018

ARAUJO, A. O.; RAMOS, M. C. P. Limitações dos relatórios de sustentabilidade para análises custo-benefício de ações sociais e ambientais. Contextus - Revista Contemporânea de Economia e Gestão, v. 13, n. 1, p. 132-155, 2015.

BAIL, G. C.; BRANCO, J. O. Pesca artesanal do camarão sete-barbas: uma caracterização sócio-econômica na Penha, SC. Brazilian Journal of Aquatic Science And Technology, v. 11, n. 2, p. 25-32, 2007.

BATISTA, M. Avaliação do impacto do plano de ordenamento da área marinha do parque natural da Arrábida na pesca comercial local. 2007. 97f. Dissertação (Mestrado) - Universidade de Lisboa, 2007.

BRANCO, J. O. Biologia e pesca do camarão sete-barbas Xiphopenaeus kroyeri (Heller) (Crustacea, Penaeidae), na Armação do Itapocoroy, Penha, SC. Revista Brasileira de Zoologia, v. 22, n. 4, p.1050-1062, 2005. http://dx.doi.org/10.1590/S010181752005000400034

CAMPOS, V. F. TQC - Controle da qualidade total: no estilo japonês. 8. ed. Belo Horizonte: INDG, 2004. 224p.

CARNEIRO, A. M. M.; DIEGUES, A. C. S.; VIEIRA, L. F. S. Extensão participativa para a sustentabilidade da pesca artesanal. Desenvolvimento e Meio Ambiente, v. 32, p. 8199, 2014. http://dx.doi.org/10.5380/dma.v32i0.35949

COELHO, V. F. Análise do processo produtivo da pesca artesanal do camarão setebarbas em penha, SC: indicadores e gestão ambiental. 2014. 73f. Dissertação (Mestrado em Ciência e Tecnologia Ambiental) - Universidade do Vale do Itajaí, Santa Catarina. 2014. 73p.

CRUZ, C. F.; MARQUES, A. L.; FERREIRA, A. C. S. Informações ambientais na contabilidade pública: reconhecimento de sua importância para a sustentabilidade. Sociedade, contabilidade e gestão, v. 4, n. 2, p. 47-60, 2009.

FOOD AND AGRICULTURE ORGANIZATION OF THE UNITED NATIONS - FAO. Projetos para barcos de pesca: 2 barcos com fundo em $\mathrm{V}$ construídos com tábuas ou compensado. Documento técnico sobre as pescas 134 Rev. 2. Roma, 2008. Disponível em: http://es.scribd.com/doc/20553752/ projetos-para-construcao-de-barcos. Acesso em: 01 maio 2015. 
INSTITUTO BRASILEIRO DE GEOGRAFIA E ESTATÍSTICA - IBGE. Dados do município de Penha, SC. $2015 . \quad$ Disponível em: http://www.cidades.ibge.gov.br/xtras/perfil. php?lang=ecodmun=421250. Acesso em: 01 maio 2015.

INTERNATIONAL PAINT. Ficha de informação de segurança para produtos químicos: YKA923, Tinta Toplac Squall Blue, vol. 1, 14 Ago. 2009a.

INTERNATIONAL PAINT. Ficha de informação de segurança para produtos químicos: YBA993, Tinta Micron Optima Activator Black, Part B, vol. 8, 6 Ago 2009b.

KALIKOSKI, D. C.; SEIXAS, C. S.; ALMUDI, T. Gestão compartilhada e comunitária da pesca no Brasil: avanços e desafios. Ambiente \& Sociedade, v. 12, n. 1, p. 151-172, 2009.

KRISTENSEN, P. The DPSIR Framework. Aarhus: National Environmental Research Institute of Denmark, 2004. 10p.

LIPIETZ, A. Questões sobre os “bens comuns”. Revista Passerelle, n. 6, p. 20-26, 2012.

MARTINS, P. G.; LAUGENI, F. P. Administração da produção. 2. ed. São Paulo: Saraiva, 2006. 562p.

PEREIRA, D. L.; PILATTI, L. A.; FASCINA. M. M.; ZAHAIKEVITCH, E. V.; CRUZ, J. C.; FRANCISCO, A. C. A controladoria e sua relação com o planejamento estratégico: o caso de uma multinacional no interior do Paraná. Revista Eletrônica Fafit/Facic, v. 2, n. 2, p. 11-21, 2011.

PEREIRA, V. C.; GONZÁLEZ, S. R. O debate acerca das insuficiências da modernização ecológica para pensar a sustentabilidade ambiental na agricultura em tempos de mudanças climáticas. Observatorio de la Economía Latinoamericana, v. 199, p. 115, 2014.

PETROBRAS. Fichas de informação de segurança de produto químico: BR0109 Óleo Diesel S500, vol.1, 03 de Janeiro; BR0006_P Lubrax Náutica Diesel, vol. 0.4P, 28 de Janeiro 2011.

PFITSCHER, E. D. Gestão e sustentabilidade através da contabilidade e controladoria ambiental: estudo de caso na cadeia produtiva de arroz ecológico. 2004. 252f. Tese (Doutorado em Engenharia de Produção) - Universidade Federal de Santa Catarina, Florianópolis, 2004.

REIS, L. G.; NOGUEIRA, D. R.; TARIFA, M. R. Uma análise histórica das publicações existentes sobre o tema contabilidade ambiental. Revista de Estudos Contábeis, v. 2, n. 3, p. 90-97, 2011.

RITZMAN, L. P.; KRAJEWSKI, L. J. Administração da produção e operações. São Paulo: Prentice Hall, 2004. 419p.

SANN, A. L. A questão da sobrecapacidade e dos direitos de pesca. Resposta ao livro verde das pescas da Comissão Europeia. Revista Passerelle, n. 6, p. 51-54, 2012.

SILVA, A. R.; CRUZ, C. V. O. A. A importância da contabilidade ambiental no mundo globalizado. UNOPAR Científica Ciências Jurídicas e Empresariais, v. 8, p. 81-87, 2014. 
SILVA GOMES, S. M. D.; SAMPAIO, M. S.; AZEVEDO, T. C.; SLOMSKI, V. G. Proposta para o ensino da controladoria ambiental nos cursos de graduação de ciências contábeis nas IESS brasileiras. Revista de Gestão Social e Ambiental, v. 6, n. 1, p. 177-189, 2012. 